\title{
Digital Phenotyping to Enhance Substance Use Treatment During the COVID-19 Pandemic
}

\author{
Michael Hsu ${ }^{1}$, MD; David K Ahern², PhD; Joji Suzuki ${ }^{3}$, MD \\ ${ }^{1}$ Department of Psychiatry, Brigham and Women's Hospital, Boston, MA, United States \\ ${ }^{2}$ Digital Behavioral Health and Informatics Research Program, Brigham and Women's Hospital, Boston, MA, United States \\ ${ }^{3}$ Division of Addiction Psychiatry, Brigham and Women's Hospital, Boston, MA, United States
}

Corresponding Author:

Michael Hsu, MD

Department of Psychiatry

Brigham and Women's Hospital

75 Francis Street

Boston, MA, 02115

United States

Phone: 16177325000

Email: mhsu7@partners.org

\begin{abstract}
Due to the COVID-19 pandemic, many clinical addiction treatment programs have been required to transition to telephonic or virtual visits. Novel solutions are needed to enhance substance use treatment during a time when many patients are disconnected from clinical care and social support. Digital phenotyping, which leverages the unique functionality of smartphone sensors (GPS, social behavior, and typing patterns), can buttress clinical treatment in a remote, scalable fashion. Specifically, digital phenotyping has the potential to improve relapse prediction and intervention, relapse detection, and overdose intervention. Digital phenotyping may enhance relapse prediction through coupling machine learning algorithms with the enormous amount of collected behavioral data. Activity-based analysis in real time can potentially be used to prevent relapse by warning substance users when they approach locational triggers such as bars or liquor stores. Wearable devices detect when a person has relapsed to substances through measuring physiological changes such as electrodermal activity and locomotion. Despite the initial promise of this approach, privacy, security, and barriers to access are important issues to address.
\end{abstract}

(JMIR Ment Health 2020;7(10):e21814) doi: 10.2196/21814

\section{KEYWORDS}

digital phenotyping; digital psychiatry; addiction; psychiatry; coronavirus; COVID-19; digital health; treatment; drugs; substance use disorder

\section{Introduction}

The COVID-19 pandemic has presented unprecedented challenges to the addiction community. First, drug-seeking behaviors can increase exposure to COVID-19. The converse is also true in that pulmonary sequelae from methamphetamine or tetrahydrocannabinol (THC) use may confer higher risk for contracting COVID-19 and may lead to more severe comorbidities for those infected with the virus [1]. Secondly, the COVID-19 pandemic is likely heightening the risk of substance use relapse [2]. Many substance users now live in greater isolation with fewer social supports, diminished access to substance use treatment, and fewer distractions from substance use [3]. Quarantine and social distancing are associated with fear, anxiety, and boredom, which are known risk factors for relapse [4]. Finally, the COVID-19 pandemic has limited our ability to monitor patients' progress and deliver adequate care. In our outpatient addiction center, we have suspended toxicology testing, which was critical in monitoring adherence to treatments such as buprenorphine. Whereas we previously relied heavily on in-person group treatment, most visits are now conducted on the internet and on an individual basis.

To address the clinical gap engendered by the pandemic, we recommended that our patients pursue web- or audio-based Alcoholics Anonymous and Narcotics Anonymous groups, which are largely unvetted substitutes, as well as evidence-supported web-based therapies such as cognitive behavioral therapy $[5,6]$. The Substance Abuse and Mental Health Services Administration (SAMHSA) and Drug 
Enforcement Administration (DEA) have administered policies enabling virtually supported, take-home buprenorphine induction and have created opportunities for patients to access a buprenorphine hotline [7] and virtual bridge clinic (currently implemented at our institution). Whether these efforts can serve as adequate substitutes for in-person addiction treatment remains to be seen; meanwhile, we need additional, scalable strategies to assist in substance use monitoring and treatment in ways that are practical and acceptable.
Digital phenotyping or behavioral sensing [8] uses passively collected, real-time data (eg, GPS tracking, social patterns, typing patterns) from patients' smartphones to inform clinical assessment, predict changes in clinical status, and deliver on-demand interventions in a scalable, cost-effective manner (Figure 1). Smartphone ownership is nearly ubiquitous in the United States, even among individuals with substance use disorders, and possesses a vast array of functionality that can be leveraged for clinical purposes $[9,10]$.

Figure 1. Digital phenotyping implements smartphone sensors to collect passive data that can then inform clinical diagnosis, risk prediction, treatment, and symptom monitoring [11].

\begin{tabular}{|c|c|}
\hline Smartphone sens & Phenotype \\
\hline 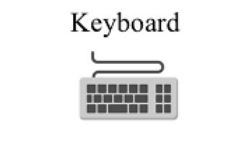 & $\begin{array}{ll}\text { - } & \text { Coordination } \\
\text { - } & \text { Impulsivity } \\
\text { - } & \text { Reaction } \\
\text { - } & \text { Concentration }\end{array}$ \\
\hline Accelerometer & $\begin{array}{l}\text { - Psychomotor dysfunction } \\
\text { - Activity level } \\
\text { - Sleep }\end{array}$ \\
\hline Phone/microphone & $\begin{array}{ll}\text { - } & \text { Prosody } \\
\text { - } & \text { Coherence } \\
\text { - } & \text { Social dynamics } \\
\text { Speech volume/rate }\end{array}$ \\
\hline Text log & $\begin{array}{ll}\text { - } & \text { Suicidal ideation } \\
\text { - } & \text { Social dynamics } \\
\text { - Connectivity }\end{array}$ \\
\hline GPS & $\begin{array}{ll}\text { - } & \text { Activity level } \\
\text { - Sleep }\end{array}$ \\
\hline
\end{tabular}

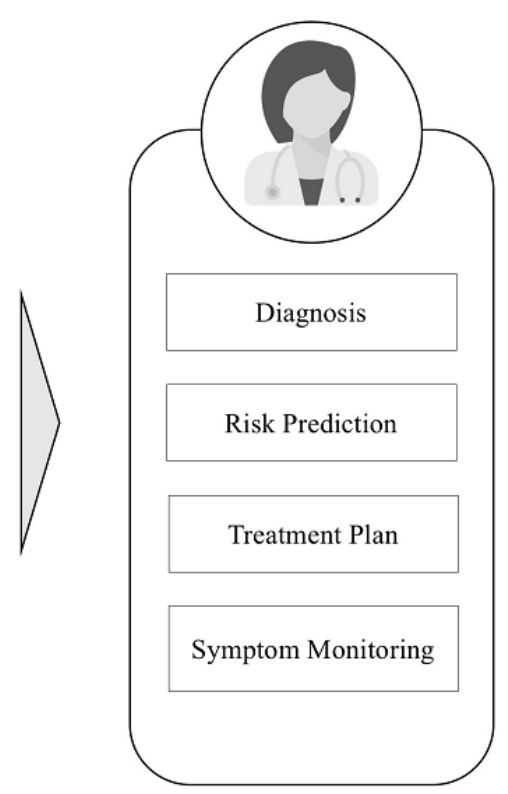

Digital phenotyping is an especially attractive clinical tool for substance use treatment during the COVID-19 pandemic, as it not only operates remotely but is also convenient for patients (no active input required), is not administratively burdensome, and may be an effective way to address historic challenges in detecting problematic substance use behaviors and delivering timely clinical interventions. Digital phenotyping has shown initial success in relapse prediction for schizophrenia [12], bipolar disorder [13,14], and mood disorder detection [14]. We describe three broad applications of digital phenotyping for addiction treatment, highlighting their potential clinical use, state of evidence, and next steps for implementation.

\section{Application 1: Relapse Prediction and Intervention}

Digital phenotyping has significant potential to enhance relapse prediction. Even before the COVID-19 pandemic, relapse was common, with prevalence rates ranging from $40 \%$ to $75 \%$ depending on the substance and the definition used in the study [15-17]. Machine learning tools based on survey responses of demographics, alcohol use, and psychological factors have $77 \%$ predictive accuracy for alcohol relapse [18]. Activity-based analysis, also known as location-based activity, analyzes how individuals' locational or GPS data correlate with their affect, thoughts, and behavior. Dr David Epstein's group combined passive geographical input with machine learning tools to predict opioid drug craving or stress 90 minutes into the future among patients with opioid use disorder on maintenance buprenorphine or methadone; they achieved a positive predictive value of 0.93 [19]. Another ongoing study by Curtin et al [20] implements digital phenotyping based on machine learning tools and contextualized static and dynamic risk signals to predict lapse in opioid use disorder. Activity-based analysis can theoretically be personalized based on regions of risk that are specific to the individual.

Automated messages can be sent to patients who are flagged as being at high risk of relapse, including warning messages, motivational messages, or recommendations to schedule follow-up appointments. A-CHESS (Addiction-Comprehensive Health Enhancement Support System), a multifeature randomized controlled trial-backed mobile app suite that supports alcohol recovery, delivers an alert to patients when their GPS indicates they are approaching a liquor store or bar [21]. Clinicians can also use this data to triage limited administrative resources by prioritizing follow-up to higher-risk patients. 
While digital phenotyping shows initial promise in enhancing relapse prediction, nearly all studies to date have been pilot studies conducted in selected patient populations. Further studies highlighting population-level outcomes such as hospitalization and prediction accuracy, especially when coupled with clinical interventions, are needed. Prior to clinical implementation, patient acceptability and feasibility of use in the clinical setting should be further explored. Other dynamic factors for substance use relapse, such as one's social environment, can be incorporated to fine-tune the predictive power of these interventions [22].

\section{Application 2: Relapse Detection}

Digital phenotyping can potentially be used to detect when a patient has relapsed. One pilot study of 30 emergency room patients demonstrated that a biosensor that collects electrodermal activity, locomotion data, and skin temperature was able to detect opioid use and distinguish between heavy and nonheavy opioid users [23]. Another study describes a wearable biosensor that can monitor alcohol consumption through detection of ethyl glucuronide in human sweat, although further population-based studies are needed to establish its acceptability and efficacy [24]. Heart-rate variability (HRV) has also been shown to be linked to alcohol use and smoking; however, specificity is an issue, as HRV is also impacted by affective disorders and trauma [25].

Once the system has detected potential relapse, an automated message can then be relayed to accountability partners (eg, family or friends), front-line staff, or clinicians. Third parties can reach out to patients who have a strong signal of relapse or repeated signals of relapse to confirm and ascertain the nature of the relapse, provide counsel over the phone, set up follow-up appointments, or offer appropriate addiction services. Wearable biosensors could potentially be used as a proxy for urine toxicology screening when monitoring for substance use, especially for patients at high risk for contracting COVID-19. Importantly, clinicians should empower patients to decide how their data will be used and obtain appropriate consent before it can be shared with third parties.

\section{Application 3: Early Overdose Detection}

Physical distancing during the COVID-19 pandemic can be life-threatening for individuals who use opioids due to increased overdose deaths from using in isolation, supply chain disruptions, and increased relapse [7,26]. Nandakumar et al [27] developed a potentially lifesaving contactless mobile phone app to detect opioid overdose by measuring respiratory rate using a short-range active sonar through a mobile phone. Their algorithm was able to detect 19/20 (95\%) of simulated overdoses in the operating room. Although this proof-of-concept app is promising, further population-based studies are needed to optimize and demonstrate its efficacy.

In theory, a device could automatically alert emergency medical services (EMS), authorized friends, and clinicians of a potential opioid overdose. Providers should empower patients to decide who is notified of the overdose, as patients may not want EMS or police to be automatically informed. Instead, they may prefer friends, neighbors, providers, or other public health professionals to be alerted first. In this case, third parties can check in with the patient, and if there is no response within a certain time frame and appropriate concern for overdose, they can administer naloxone (if they are trained to do so and are in the vicinity) and consider whether to bring the patient to the emergency room or involve first responders.

\section{Limitations to Digital Phenotyping}

There are several notable limitations to digital phenotyping and barriers to implementation that should be addressed. First, security and privacy are critically important concerns. Data stored on a mobile phone or cloud service may be vulnerable to security threats such as password compromise, while data uploaded to an electronic medical record system may be accessed by third parties [11,28]. Although call log, GPS, and accelerometer data are often anonymized by application developers, a theoretical risk remains that third parties can identify individuals based on raw data [29]. Clinicians should thoroughly vet digital phenotyping applications based on the App Evaluation Model developed by the American Psychiatric Association to ensure the safety and privacy of identifiable patient data [30,31]. Providers should protect patient data and counsel patients regarding privacy risks, especially for vulnerable individuals such as those with mental illness or substance use disorders.

Second, further studies are needed to assess the acceptability and feasibility of digital phenotyping among patients with substance use disorders. As is the case with all digital health technologies, the clinical efficacy of an app does not always translate to user adoption. Lowering barriers to entry such as improving user friendliness and addressing technology illiteracy are important.

Third, inequality of access to smartphone technology is problematic, especially among individuals who are of lower socioeconomic status, aged 85 years or older, widowed, Medicaid recipients, Black or Hispanic, and have disabilities [32]. However, many state Medicaid programs now offer free mobile phones to eligible recipients, and federal programs such as the Federal Communications Commission's Lifeline Program offer a subsidy for cellular and data service plans to low-income individuals $[33,34]$. Lack of broadband access may be a barrier, especially for rural and underserved communities [35]. Further research on these barriers to access is needed to devise apt solutions to equip even the most marginalized and vulnerable populations with digital technology.

Finally, there are salient administrative and financial barriers to clinical implementation. While there may be long-term cost savings in the reduction of health care use and less labor-intensive means of substance use monitoring, introducing any new health technology requires an initial resource investment. Patients and staff need to be trained on the technology and the clinical integration of the data streams generated by digital phenotyping applications. To move beyond resource-rich academic and research settings, clinician time and use of digital phenotyping will need reimbursement by payors, 
which requires demonstrating the clinical and financial value of the technology to insurance companies. This supports the call for methodologically rigorous studies to determine how the initially promising experimental outcomes of digital phenotyping translate to real-world clinical value.

\section{Conclusions}

Digital phenotyping has tremendous potential to augment substance use treatment, especially during the COVID-19 pandemic. Specifically, this technology can help address significant challenges in improving care for substance use disorders in the areas of relapse prediction and intervention, relapse detection, and overdose detection. Despite the promise and potential of digital phenotyping, many studies thus far have been proof-of-concept or pilot studies in siloed patient populations; more robust, generalizable experiments are needed to demonstrate clinical efficacy, acceptability, and feasibility. Iterative observation and experimentation can allow for further refinement of the underlying technology and how it will be clinically integrated. Concerns of privacy, security, equity, and sustainability need to be addressed.

\section{Acknowledgments}

This work was supported by an NIH/NIDA grant (K23DA042326).

\section{Conflicts of Interest}

None declared.

\section{References}

1. Volkow ND. Collision of the COVID-19 and Addiction Epidemics. Ann Intern Med 2020 Jul 07;173(1):61-62. [doi: $10.7326 / \mathrm{m} 20-1212]$

2. Hoffman J. With meetings banned, millions struggle to stay sober on their own. New York Times. 2020 Mar 26. URL: https://www.nytimes.com/2020/03/26/health/coronavirus-alcoholics-drugs-online.html [accessed 2020-10-22]

3. Silva MJ, Kelly Z. The escalation of the opioid epidemic due to COVID-19 and resulting lessons about treatment alternatives. Am J Manag Care 2020 Jul 01;26(7):e202-e204 [FREE Full text] [doi: 10.37765/ajmc.2020.43386] [Medline: 32672917]

4. Parvaz MA, Moeller SJ, Goldstein RZ. Incubation of Cue-Induced Craving in Adults Addicted to Cocaine Measured by Electroencephalography. JAMA Psychiatry 2016 Nov 01;73(11):1127-1134 [FREE Full text] [doi:

10.1001/jamapsychiatry.2016.2181] [Medline: 27603142]

5. Carroll KM, Ball SA, Martino S, Nich C, Babuscio TA, Nuro KF, et al. Computer-assisted delivery of cognitive-behavioral therapy for addiction: a randomized trial of CBT4CBT. Am J Psychiatry 2008 Jul;165(7):881-888 [FREE Full text] [doi: 10.1176/appi.ajp.2008.07111835] [Medline: 18450927]

6. Kiluk BD, Carroll KM. New developments in behavioral treatments for substance use disorders. Curr Psychiatry Rep 2013 Dec 1;15(12):420 [FREE Full text] [doi: 10.1007/s11920-013-0420-1] [Medline: 24173656]

7. Samuels EA, Clark SA, Wunsch C, Jordison Keeler LA, Reddy N, Vanjani R, et al. Innovation During COVID-19: Improving Addiction Treatment Access. J Addict Med 2020;14(4):e8-e9 [FREE Full text] [doi: 10.1097/ADM.0000000000000685] [Medline: 32404652]

8. Mohr DC, Shilton K, Hotopf M. Digital phenotyping, behavioral sensing, or personal sensing: names and transparency in the digital age. NPJ Digit Med 2020 Mar 25;3(1):45. [doi: 10.1038/s41746-020-0251-5] [Medline: $\underline{32219186]}$

9. Dahne J, Lejuez CW. Smartphone and Mobile Application Utilization Prior to and Following Treatment Among Individuals Enrolled in Residential Substance Use Treatment. J Subst Abuse Treat 2015 Nov;58:95-99 [FREE Full text] [doi: 10.1016/j.jsat.2015.06.017] [Medline: 26231698]

10. Masson CL, Chen IQ, Levine JA, Shopshire MS, Sorensen JL. Health-related internet use among opioid treatment patients. Addict Behav Rep 2019 Jun;9:100157 [FREE Full text] [doi: 10.1016/j.abrep.2018.100157] [Medline: 31193741]

11. Hsu M, Lipschitz J, Boland R, Torous J. Innovative and Evolving Mobile Mental Health Technologies for the Treatment of Serious Mental Illness. In: Reger GM, editor. Technology and Mental Health: A Clinician's Guide to Improving Outcomes. Oxfordshire, UK: Routledge; Oct 12, 2020:107-126.

12. Barnett I, Torous J, Staples P, Sandoval L, Keshavan M, Onnela J. Relapse prediction in schizophrenia through digital phenotyping: a pilot study. Neuropsychopharmacology 2018 Jul;43(8):1660-1666 [FREE Full text] [doi: 10.1038/s41386-018-0030-z] [Medline: 29511333]

13. Faurholt-Jepsen M, Vinberg M, Frost M, Christensen EM, Bardram JE, Kessing LV. Smartphone data as an electronic biomarker of illness activity in bipolar disorder. Bipolar Disord 2015 Nov;17(7):715-728. [doi: 10.1111/bdi.12332] [Medline: 26395972]

14. Jacobson NC, Weingarden H, Wilhelm S. Digital biomarkers of mood disorders and symptom change. NPJ Digit Med 2019 Feb 1;2(1):3 [FREE Full text] [doi: 10.1038/s41746-019-0078-0] [Medline: 31304353]

15. Alterman AI, McKay JR, Mulvaney FD, Cnaan A, Cacciola JS, Tourian KA, et al. Baseline prediction of 7-month cocaine abstinence for cocaine dependence patients. Drug and Alcohol Dependence 2000 Jun;59(3):215-221. [doi:

10.1016/s0376-8716(99)00124-6] 
16. Andersson HW, Wenaas M, Nordfjærn T. Relapse after inpatient substance use treatment: A prospective cohort study among users of illicit substances. Addict Behav 2019 Mar;90:222-228 [FREE Full text] [doi: 10.1016/j.addbeh.2018.11.008] [Medline: 30447514]

17. Pasareanu AR, Vederhus J, Opsal A, Kristensen $\emptyset$, Clausen T. Improved drug-use patterns at 6 months post-discharge from inpatient substance use disorder treatment: results from compulsorily and voluntarily admitted patients. BMC Health Serv Res 2016 Jul 20;16(1):291 [FREE Full text] [doi: 10.1186/s12913-016-1548-6] [Medline: 27439499]

18. Connor JP, Symons M, Feeney GFX, Young RM, Wiles J. The application of machine learning techniques as an adjunct to clinical decision making in alcohol dependence treatment. Subst Use Misuse 2007;42(14):2193-2206. [doi: 10.1080/10826080701658125] [Medline: 18098000 ]

19. Epstein DH, Tyburski M, Kowalczyk WJ, Burgess-Hull AJ, Phillips KA, Curtis BL, et al. Prediction of stress and drug craving ninety minutes in the future with passively collected GPS data. NPJ Digit Med 2020 Mar 4;3(1). [doi:

10.1038/s41746-020-0234-6]

20. Curtin J, Dhavan, Shah D, Zhu X, Gustafson D, Brown R, et al. Contextualized daily prediction of lapse risk in opioid use disorder by digital phenotyping. University of Wisconsin Addiction Research Center. 2019 Aug 01. URL: https://arc. psych.wisc.edu/lapse-risk-opioid/ [accessed 2020-06-02]

21. Gustafson DH, McTavish FM, Chih M, Atwood AK, Johnson RA, Boyle MG, et al. A smartphone application to support recovery from alcoholism: a randomized clinical trial. JAMA Psychiatry 2014 May;71(5):566-572 [FREE Full text] [doi: 10.1001/jamapsychiatry.2013.4642] [Medline: 24671165]

22. Owens MD, McCrady BS. The Role of the Social Environment in Alcohol or Drug Relapse of Probationers Recently Released From Jail. Addict Disord Treat 2014;13(4):179-189. [doi: 10.1097/adt.0000000000000039]

23. Carreiro S, Wittbold K, Indic P, Fang H, Zhang J, Boyer EW. Wearable Biosensors to Detect Physiologic Change During Opioid Use. J Med Toxicol 2016 Sep 22;12(3):255-262 [FREE Full text] [doi: 10.1007/s13181-016-0557-5] [Medline: 27334894]

24. Selvam AP, Muthukumar S, Kamakoti V, Prasad S. A wearable biochemical sensor for monitoring alcohol consumption lifestyle through Ethyl glucuronide (EtG) detection in human sweat. Sci Rep 2016 Mar 21;6(1):23111 [FREE Full text] [doi: 10.1038/srep23111] [Medline: 26996103]

25. Yuksel R, Yuksel RN, Sengezer T, Dane S. Autonomic Cardiac Activity in Patients with Smoking and Alcohol Addiction by Heart Rate Variability Analysis. Clin Invest Med 2016 Dec 01;39(6):147. [doi: 10.25011/cim.v39i6.27519]

26. Alexander GC, Stoller KB, Haffajee RL, Saloner B. An Epidemic in the Midst of a Pandemic: Opioid Use Disorder and COVID-19. Ann Intern Med 2020 Jul 07;173(1):57-58. [doi: 10.7326/m20-1141]

27. Nandakumar R, Gollakota S, Sunshine JE. Opioid overdose detection using smartphones. Sci Transl Med 2019 Jan 09;11(474). [doi: 10.1126/scitranslmed.aau8914] [Medline: 30626717]

28. White R. Electronic Health Records: Balancing Progress and Privacy. The Hastings Center. 2012 Jun 19. URL: https:/ /www.thehastingscenter.org/electronic-health-records-balancing-progress-and-privacy/ [accessed 2020-10-22]

29. Grundy Q, Chiu K, Held F, Continella A, Bero L, Holz R. Data sharing practices of medicines related apps and the mobile ecosystem: traffic, content, and network analysis. BMJ 2019 Mar 20;364:1920. [doi: 10.1136/bmj.1920] [Medline: 30894349]

30. The App Evaluation Model. App Advisor: An American Psychiatric Association Initiative. URL: https://www.psychiatry.org/ psychiatrists/practice/mental-health-apps/the-app-evaluation-model [accessed 2020-10-22]

31. Henson P, David G, Albright K, Torous J. Deriving a practical framework for the evaluation of health apps. Lancet Digit Health 2019 Jun;1(2):e52-e54. [doi: 10.1016/s2589-7500(19)30013-5]

32. Roberts ET, Mehrotra A. Assessment of Disparities in Digital Access Among Medicare Beneficiaries and Implications for Telemedicine. JAMA Intern Med 2020 Aug 03;180(10):1386-1389. [doi: 10.1001/jamainternmed.2020.2666] [Medline: 32744601]

33. Free Cell Phones for Medicaid Recipients. Medicaidcellphone.com. 2014. URL: http://medicaidcellphone.com/ [accessed 2020-10-22]

34. Lifeline program for low-income consumers. Federal Communications Commission. 2020 Aug 05. URL: https://www. fcc.gov/general/lifeline-program-low-income-consumers [accessed 2020-08-09]

35. Hesse BW, Ahern D, Ellison M, Aronoff-Spencer E, Vanderpool RC, Onyeije K, et al. Barn-Raising on the Digital Frontier: The L.A.U.N.C.H. Collaborative. J Appalach Health 2020;2(1):6-20. [doi: 10.13023/jah.0201.02]

\author{
Abbreviations \\ A-CHESS: Addiction-Comprehensive Health Enhancement Support System \\ DEA: Drug Enforcement Administration \\ EMS: emergency medical services \\ HRV: heart-rate variability \\ SAMHSA: Substance Abuse and Mental Health Services Administration \\ THC: tetrahydrocannabinol
}


Edited by J Torous; submitted 28.06.20; peer-reviewed by S Sanchez, B Johnson; comments to author 25.07.20; revised version received 14.08.20; accepted 25.09.20; published 26.10.20

Please cite as:

Hsu M, Ahern DK, Suzuki J

Digital Phenotyping to Enhance Substance Use Treatment During the COVID-19 Pandemic

JMIR Ment Health 2020;7(10):e21814

URL: http://mental.jmir.org/2020/10/e21814/

doi: $10.2196 / 21814$

PMID: 33031044

CMichael Hsu, David K Ahern, Joji Suzuki. Originally published in JMIR Mental Health (http://mental.jmir.org), 26.10.2020. This is an open-access article distributed under the terms of the Creative Commons Attribution License (https://creativecommons.org/licenses/by/4.0/), which permits unrestricted use, distribution, and reproduction in any medium, provided the original work, first published in JMIR Mental Health, is properly cited. The complete bibliographic information, a link to the original publication on http://mental.jmir.org/, as well as this copyright and license information must be included. 